\title{
Life-threatening Tracheal Benign Tumor: Lipoma
}

\author{
Biing-Ru Wu ${ }^{1}$, Chia-Hung Chen ${ }^{1,2}$, Wei-Chih Liao ${ }^{1,2}$ and Wen-Chien Cheng ${ }^{1,2}$
}

Key words: tracheal lipoma, bronchoscope, stridor

(Intern Med 55: 1677-1678, 2016)

(DOI: 10.2169/internalmedicine.55.6334)

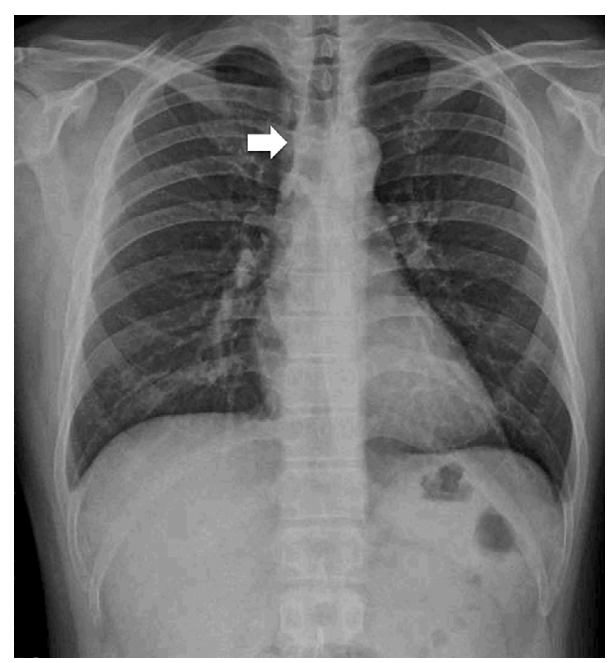

Picture 1.

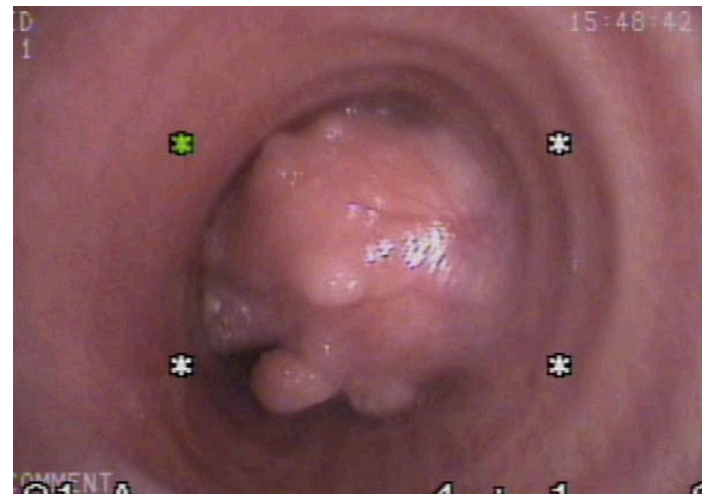

Picture 3.

A 35-year-old man presented to the emergency room with near-fatal dyspnea. Six months earlier, he suffered from a non-productive cough and progressive dyspnea and was previously treated for asthma. On examination, stridor was noted. Chest radiography revealed a soft tissue density mass in the trachea (Picture 1) and computed tomography re-

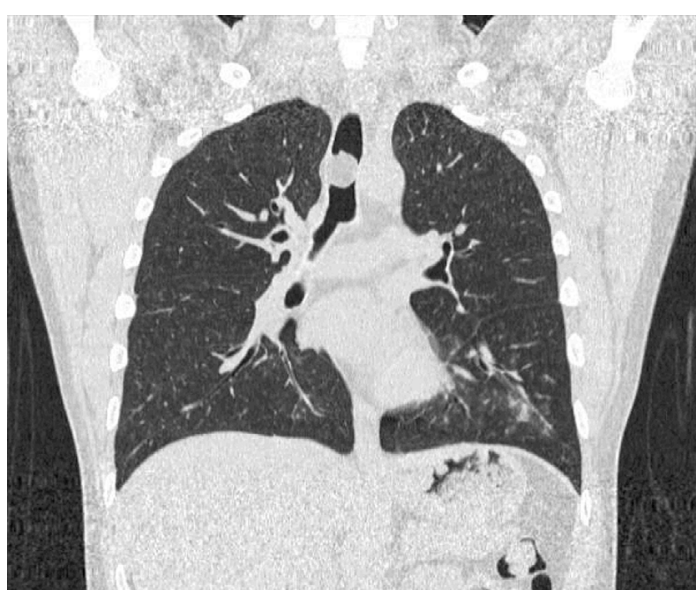

Picture 2.

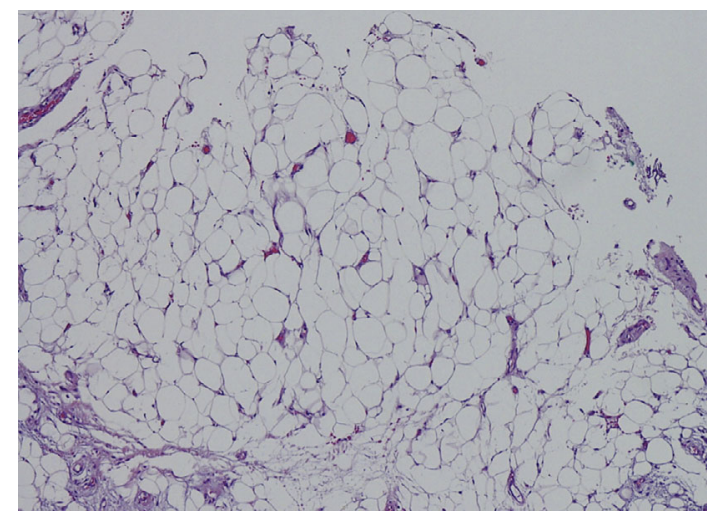

Picture 4.

vealed an endotracheal soft tissue tumor obliterating more than $90 \%$ of the trachea diameter (Picture 2). He underwent emergency flexible bronchoscopy with tumor resection (Picture 3). The tumor was pathologically diagnosed as a tracheal lipoma (Picture 4).

Most tumors of the tracheobronchial tree are malignant.

${ }^{1}$ Division of Pulmonary and Critical Care Medicine, Department of Internal Medicine, China Medical University Hospital, Taiwan and ${ }^{2}$ Graduate Institute of Clinical Medical Science, College of Medicine, China Medical University, Taiwan

Received for publication August 8, 2015; Accepted for publication September 27, 2015

Correspondence to Dr. Wen-Chien Cheng, wcchengdr@gmail.com 
Benign pulmonary tumors are rare, with lipoma being extremely rare (1). Trachea lipoma is histologically benign and can cause an airway obstruction. Treatment can include bronchoscopy; however, if bronchoscopic management is not possible, surgical resection should therefore be considered before it leads to death (2).

The authors state that they have no Conflict of Interest (COI).

\section{References}

1. Gamblin TC, Farmer LA, Dean RJ, Bradley RA, Dalton ML. Tracheal polyp. Ann Thorac Surg 73: 1286-1287, 2002.

2. Basoglu A, Celik B, Akdag AO, Sengul AT. Endobronchial lipoma: a rare cause of bronchial occlusion. Interact Cardiovasc Thorac Surg 3: 263-264, 2004.

(C) 2016 The Japanese Society of Internal Medicine http://www.naika.or.jp/imonline/index.html 